Lexis Vol. XLIV (2) 2020: 407-444

\title{
La fraseología en El Trajumán de Michael Papo (1884)
}

\author{
Maria Eugênia Olímpio de Oliveira Silva \\ Universidad de Alcalá (España) \\ Encarnación Tabares Plasencia \\ Carsten Sinner \\ Universität Leipzig (Alemania) \\ Elia Hernández Socas \\ Universidad de La Laguna (España)
}

\section{RESUMEN}

El presente estudio analiza, desde el punto de vista de la Fraseología como subdisciplina lingüística, una obra judeoespañola, El Trajumán, de Michael Papo, publicada en Viena en 1884. Nuestro objetivo es establecer las relaciones de las unidades fraseológicas (UF) judeoespañolas de la obra con las del español general y los elementos prestados o calcados de otras lenguas. Para ello, se ha efectuado la detección y extracción de los fraseologismos, su análisis y su catalogación de acuerdo con el modelo de Corpas (1996) con ciertas desviaciones conceptuales (Penadés 2012, López Simó 2016, Núñez Bayo 2016). Centrándonos en las locuciones y fórmulas, los principales resultados parecen apuntar, desde el punto de vista cuantitativo, a la existencia de un mayor número de las primeras frente a las fórmulas; desde un punto de vista cualitativo, a la presencia de (1) unidades propias

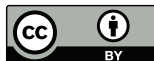

https://doi.org/10.18800/lexis.202002.002 
del español general; (2) fraseologismos que suponen variantes formales de UF del español general, entre las que destacan las que contienen elementos léxicos tomados en préstamo de otras lenguas; (3) algunas UF que parecen calcos semánticos del alemán o del francés.

Palabras clave: fraseología, judeoespañol, locuciones, fórmulas

Phraseology in El Trajumán by M. Papo (1884)

\section{Abstract}

The paper analyses a Judeo-Spanish publication, The Trajumán, published in Vienna by Michael Papo, from the point of view of Phraseology as a linguistic subdiscipline. Our aim here is to establish the relation of the Judeo-Spanish phraseological units (PhU) of the publication dealt with here with those of Spanish in general and with the elements borrowed from other languages or loan translations. For this purpose, we carried out a detailed analysis in order to determine, study and classify the PhU according to Corpas' model (1996), with certain conceptual adaptations (Penadés 2012, López Simó 2016, Núñez Bayo 2016). From a quantitative perspective, the main results of our study, regarding idioms and formulaic expressions, seem to indicate, the existence of a greater number of idioms, as opposed to formulaic expressions. From a qualitative perspective, the study shows (1) the presence of PhU of Spanish in general, (2) the presence of phraseologisms that can be considered formal variants of general Spanish (some of them contain lexical elements borrowed from other languages and have to be mentioned apart) and (3) the existence of some $\mathrm{PhU}$ that seem to be loan translations from German or French.

Keywords: Phraseology, Judeo-Spanish, idioms, formulaic expressions

\section{Introducción}

En 1884 se publica en Viena El Trajumán o livro de converśación en español y alemán (nemŝesco) por provecho de muchos siñores del Oriente que viajan a_la Nemŝia recoǵido de los mijores livros de converśación que [b]ay en ditas lenguas por el minor: Menabem 
b. Michael Papo. Su autor, Michael Papo, nació, según el testimonio que nos proporciona Heuer (1984: 149), en Sarajevo el 15 de diciembre de 1843 y falleció el 29 de enero de 1918 en Viena. Otras fuentes (Lippe 1881: 358; Kayserling [1890] 2001: 84; Wininger 1929: 605, entre otros) coinciden en el dato de que fue rabino de la comunidad israelita española de Viena; Studemund-Halevy y Collin (2008: 163 y siguientes) completan esta información señalando que fue, además, una figura muy influyente en esta comunidad. Posiblemente, por sus orígenes bosnios, debió de ocupar un puesto de relevancia como mediador entre grupos de judíos sefardíes de los Balcanes, llegados a Viena en el último tercio del siglo XIX, y la sociedad judía de esta ciudad. Aparte de la obra que nos ocupa, solo nos consta la existencia de dos obras más que puedan atribuirse a su autoría - todas ellas publicadas en Viena-: una traducción en judeoespañol (en rasí) de la obra de Adolf von Zemlinsky, Geschichte der türkisch-israelitischen Gemeinde zu Wien, von ibrer Gründung bis heute (Wininger 1929: 605; Heuer 1984: 149) y una edición del Seder Tefilá o libro de oraciones cotidianas judías de 1908 (Studemund-Halévy y Collin 2008: 179).

El Trajumán, del que se está preparando una edición transcrita y comentada por parte de Sinner, Tabares Plasencia y Hernández Socas, constituye una guía de conversación judeoespañol-alemán, pensada para judíos sefardíes que viajaran a Austria o a las regiones de lengua alemana del Imperio austro-húngaro'.

Entre los numerosos puntos de interés que ofrece se encuentra la fraseología que se recoge. Por ello, nos planteamos la extracción

\footnotetext{
1 En el título encontramos una referencia vaga a las posibles fuentes empleadas por el autor para elaborar la obra, pues se señala que ha sido "recoǵido de los mijores livros de converśación que [h]ay en ditas lenguas” es decir, parece que utilizó otras guías de conversación, pero no menciona ninguna explícitamente. La denominada Quellenforschung es de gran interés para el conocimiento cabal de una obra, pero, a la vez, puede resultar una labor muy ardua. En la actualidad, dentro del grupo de investigación "Sephardenspanisch" de la Universidad de Leipzig se está desarrollando esta tarea, cuyos resultados se recogerán en la edición comentada de la obra. Otro escollo que hemos tenido que salvar es la fecha de publicación de la obra (1884). Sobre su polémica datación se ofrecen más detalles en Hernández Socas, Sinner y Tabares Plasencia (2010).
} 
y análisis de las unidades fraseológicas (UF) que se contienen en ella, labor que no se había realizado hasta el momento. Por ello, en el presente artículo abordamos el estudio de los fraseologismos de El Trajumán desde la perspectiva de la moderna disciplina fraseológica con la finalidad de contribuir al desarrollo de la investigación en Fraseología en el ámbito del judeoespañol. En nuestra investigación, aparte de extraer y presentar con parámetros científicos estas unidades, nos interesa verificar, por un lado, si buena parte de los fraseologismos tiene formalmente un correlato dentro del español general y establecer si estos son expresiones españolas, variantes del español o expresiones estándares en judeoespañol (véase apartado 1.1 del trabajo en relación con la teoría de Quintana (2006) sobre el judeoespañol como lengua pluricéntrica); por otro, si otra buena parte de los fraseologismos no era ajena al fenómeno del préstamo lingüístico o, incluso, del calco (véase Gómez Capuz 2009: 2-4), por las razones que expondremos más adelante.

Tras esta introducción, nos ocupamos, en primer lugar, de la situación (socio)lingüística del judeoespañol y el papel de Viena en el fenómeno denominado "rehispanización”. En segundo lugar, ofrecemos nuestro punto de partida teórico para realizar esta investigación y un breve estado de la cuestión de los estudios de Fraseología sobre esta variedad. En tercer lugar, situamos en su contexto cultural y lingüístico la obra de Papo; sobre todo, nos centramos en su estructura, lo que permitirá comprender la información que viene a continuación, que atañe a la forma en que aparecen las UF en la obra. En cuarto lugar, presentamos la metodología empleada para efectuar el análisis y llegar a una propuesta de clasificación de las unidades recopiladas, elaborada a partir de un punto de vista intralingüístico (judeoespañol-español); asimismo, indicamos algunas de las dificultades encontradas en esta labor de identificación y categorización. Para finalizar, exponemos si se verifican nuestras ideas de partida y, concisamente, algunas perspectivas de estudio que pueden derivarse de este trabajo. 


\section{Marco teórico}

2.1. El estatuto (socio)lingüístico del judeoespañol

El fenómeno lingüístico denominado, no sin polémica, "judeoespañol” es considerado mayoritariamente por la Lingüística y Dialectología hispánicas como un dialecto o variedad históricos del español; tendría como base el romance castellano medieval, específicamente del siglo XV, y se habría forjado a lo largo de los siglos del destierro sefardí, alejado de la norma peninsular tras un proceso de koineización (Quintana 2002, 2006a, 2006b: 77; Minervini 2006). Por ello, en todas las comunidades (tanto en las creadas desde la expulsión de 1492 como en las fundadas posteriormente) hay huellas de todas las lenguas iberorromances (aragonés, asturleonés, catalán, gallego, navarro y portugués).

En esta etapa formativa, que abarcaría los siglos XVI y XVII (Minervini 2006: 19-21), estuvo también presente el italiano, lengua con la que los sefardíes no dejaron de estar vinculados hasta el siglo $\mathrm{XX}$. No puede decirse lo mismo de las lenguas de adstrato (turco, griego, alemán, etc.) o del francés. Este último influyó sobre el desarrollo del judeoespañol en periodos más tardíos; esto es, en la etapa llamada clásica (siglos XVIII-XIX)² por Minervini (2006: 24-28), caracterizada por ser una época de profundo cambio y modernización de las estructuras judías motivadas por la recepción de la Ilustración (o su vertiente judía, la Haskalab) y por el florecimiento literario en algunos centros urbanos. Asimismo, se destacó por la inclusión de numerosos galicismos, hecho propiciado por la institución educativa de la Alliance Israélite Universelle (fundada en 1860), que desempeñaría un papel decisivo en el debate generado posteriormente en torno al estatus del judeoespañol como vehículo lingüístico de los sefardíes. Así, parece que, en la etapa en que se redacta la obra aquí tratada, ya el judeoespañol presentaba los rasgos lingüísticos prototípicos con los que se le suele singularizar, a caballo entre el arcaísmo y la innovación, y que tan bien resume Bürki (2016: 152).

2 Véanse, para otras periodizaciones, Bunis (1992) y Schmid (2008). 
Ha sido la desvinculación durante siglos del judeoespañol de la norma peninsular uno de los motivos aducidos por Quintana (2010) para lanzar su tesis sobre el judeoespañol como lengua pluricéntrica desarrollada al margen del español. Esta teoría sería una aplicación de los conceptos de espacio variacional, cadena variacional y continuo concepcional de Oesterreicher (2002), y Koch y Oesterreicher (2007) al fenómeno lingüístico del judeoespañol. La cuestión de si estamos ante una variedad particular del español o una lengua propia no es baladí y resulta clave para nuestro trabajo porque, evidentemente, cambiaría la perspectiva de análisis del material fraseológico encontrado en Papo. Pues, ¿ cómo deben interpretarse las UF judeoespañolas en nuestra obra?, ¿han de ser examinadas como variantes ${ }^{3}$ del español, como expresiones estándares y diatópicas judeoespañolas? También se plantea el problema de las posibles rehispanizaciones fraseológicas. Si partimos de la tesis, como quiere Quintana, de que el judeoespañol posee estatus de lengua propia, ¿han de entenderse entonces estas rehispanizaciones como préstamos?

Sin embargo, Papo no parece percibir el judeoespañol como una lengua diferente del español (recuérdese el mismo título de la obra); de hecho, es consciente y hace partícipe al lector de su variación "en las provincias de la Turquía", lo cual le habría supuesto una dificultad para elaborar su obra e informa de su intención de usar "la [h]avla español [...] verdadera", que interpretamos como el español de la península Ibérica del momento (Papo 1884: III). Así nos lo indica la forma de proceder en el abultado número de palabras glosadas que encontramos en la obra: por lo general, es la palabra del español europeo peninsular la que aparece fuera de la glosa y la voz judeoespañola la que figura en la glosa ("cer[r]ad[a] con medias lunas", Papo 1884: III). Este hecho refleja que el autor se muestra partidario de la rehispanización, proceso que se va a desarrollar y promocionar por buena parte de la intelectualidad sefardí en Viena, como veremos en el apartado siguiente.

\footnotetext{
3 En torno al concepto de variante fraseológica desde el punto de vista de la Lingüística de Variedades, remitimos a Sinner y Tabares Plasencia (2016).
} 
2.2. Viena como centro lingüístico y cultural sefardí. La rehispanización del judeoespañol

En su monografía sobre la variación geográfica en judeoespañol, Quintana (2006a: 126-127; véase también Quintana 1997, 2002 y 2006b) habla de comunidades sefardíes en situación especial, y, concretamente, se refiere a las de Egipto y Viena. La especialidad derivaría del problema de encuadre de estas dos zonas dentro del marco de la variación diatópica del judeoespañol, dado que se trata de comunidades secundarias creadas como extensión de comunidades primarias. Específicamente, por lo que a Viena se refiere, indica la lingüista que, a pesar de acoger a sefardíes de áreas dialectales muy dispares, los datos de los que se dispone apuntan a que no se produjo un proceso de nivelación semejante a los ocurridos en la etapa formativa del judeoespañol. Por lo demás, Quintana (ibidem) destaca el dinamismo cultural de esta comunidad y el compromiso de sus intelectuales por determinar el papel que debía ocupar el judeoespañol en la sociedad sefardí. Como se ha destacado en Sinner, Hernández Socas, y Tabares Plasencia (2014a), la época en la que se halla fechada nuestra obra es conocida por el debate que se dio en torno a la función identitaria del judeoespañol (véase también Studemund-Halevy y Collin 2008: 151). Y, precisamente, Viena fue un centro de discusión importantísimo: el hecho de que el alemán fuera lengua de cultura del Imperio austrohúngaro y que la burguesía judía balcánica enviara a sus hijos a la Universidad de Viena a estudiar generó el debate de si era mejor asumir al alemán como lengua de cultura (como había ocurrido en otras comunidades con el francés) o conservar el judeoespañol modernizándolo mediante un proceso de acercamiento lingüístico al español peninsular del momento, lo que se conoce como recastellanización (Quintana 1999, aunque rehispanizar en Quintana 2010: 48) o, de forma más generalizada, rehispanización. Parece que Viena se convirtió en uno de los baluartes rehispanizadores, además de ser uno de los centros intelectuales y culturales más importantes del mundo sefardí en el siglo XIX (Quintana 2006a: 123). Prueba de ello es la obra de Papo en la que se emplean formas del castellano moderno donde deberían espe- 
rarse formas judeoespañolas y las apreciaciones acerca del español de las que se hace mención en diversos lugares de este trabajo.

\subsection{Encuadre teórico del análisis fraseológico}

Un análisis somero de El Trajumán nos revela la presencia de un dilatado número de UF, entendidas en este trabajo como unidades pluriverbales, con significado léxico o gramatical, que presentan fijación formal y semántica en grado relativo. Partimos de un modelo clasificatorio ampliamente usado en la Fraseología española, según el cual las UF se disponen en tres esferas: la de las colocaciones, las locuciones y los enunciados fraseológicos (fórmulas y paremias) (Corpas Pastor 1996). De acuerdo con esta propuesta, las UF que integran las dos primeras esferas no constituyen enunciados u oraciones; son, por el contrario, partes de estos enunciados; las UF de la tercera esfera, a su vez, sí equivalen a oraciones o enunciados, es decir, poseen autonomía textual.

Este modelo de clasificación proporciona una visión comprehensiva del hecho fraseológico, puesto que, por un lado, abarca diferentes tipos de unidades pluriverbales que comparten rasgos en común, como la fijación estructural y semántica, y que, por tanto, pueden ser objeto de estudio de la Fraseología. Por otro lado, constituye una propuesta sólida, ya que se basa en criterios objetivos, correspondientes al comportamiento lingüístico de las unidades consideradas y permite organizar un amplio conjunto de unidades. Así pues, tienen cabida en este modelo unidades que en otras propuestas teóricas quedarían fuera del ámbito de estudio de la Fraseología, como los refranes y las colocaciones ${ }^{4}$. Cabe señalar que la diversidad de propuestas clasificatorias refleja, en realidad, diferentes formas de posicionarse ante el objeto de estudio. Así,

\footnotetext{
4 Como es sabido, ya con los trabajos de Bally ([1909] 1951) y Vinográdov (1947) se ha puesto en tela de juicio la pertenencia de las paremias a este ámbito. Más recientemente, haciéndose eco de esta postura, se ha dicho incluso que "las clásicas paremias y proverbios o refranes deben ser asignados a la Paremiología” (García-Page 2008: 8) y no a la Fraseología. Además, de un tiempo a esta parte, también se ha propuesto excluir las colocaciones de los estudios fraseológicos (Penadés Martínez 2017: 124).
} 
a lo largo del tiempo, diferentes autores, siguiendo una perspectiva propia o adscribiéndose a una corriente metodológica o a una tradición fraseológica dada, han intentado ordenar o clasificar el conjunto de fraseologismos de las diferentes lenguas. En consecuencia, hoy por hoy, conviven distintos modelos de clasificación, establecidos desde criterios y procedimientos diversos. De modo general, como bien ha señalado Montoro del Arco (2006 y 2017), podemos distinguir clasificaciones realizadas en función de una perspectiva categorial discreta (concepción ancha y concepción estrecha de la fraseología) y a partir de una perspectiva categorial difusa (como, por ejemplo, las clasificaciones basadas en el rasgo de idiomaticidad y en las nociones de “centro" y “periferia”). Adoptamos aquí una concepción ancha de la Fraseología, que permite abarcar las diferentes UF presentes en Papo.

Esta variedad de fraseologismos nos ha obligado a seguir un modelo definitorio de UF diferente del propuesto por Corpas Pastor, aunque hayamos adoptado su taxonomía. Así, de acuerdo con este modelo, dentro del concepto de fórmula tienen cabida no solo la noción de fórmula rutinaria (Corpas Pastor 1996) sino también las nociones de fórmula oracional (Núñez Bayo 2016) o fórmula de la conversación (López Simó 2016). Grosso modo, bajo estos conceptos se encuentran unidades diversas que tienen en común su carácter fraseológico, es decir, su pluriverbalidad, fijación formal, especialización semántica y pragmática-discursiva, y que se diferencian según su mayor o menor autonomía - las oracionales, por ejemplo, conforman actos de habla-, y según la posibilidad de que constituyan exponentes lingüísticos de diferentes funciones comunicativas. Por lo demás, la definición de locución que hemos adoptado en este trabajo es una propuesta revisada y actualizada de la definición clásica proporcionada por Casares (1950). Siguiendo, pues, a Penadés Martínez (2012: 23), entendemos una locución como "una combinación fija de palabras que funciona como elemento de la oración y cuyo significado no se corresponde con la suma de los significados de sus componentes”. 
Los problemas de clasificación señalados anteriormente afectan, sobre todo, a la delimitación de las clases que constituirían el objeto de estudio de la Fraseología. Sin embargo, estos problemas también conciernen al establecimiento de límites entre los tipos de unidades fraseológicas que deben incluirse en cada clase o esfera. Esta cuestión ha sido ampliamente discutida, ya que no siempre es fácil deslindar las diferentes clases de fraseologismos. En efecto, según la perspectiva teórica que se asuma, un ejemplo dado de unidad fraseológica puede ser asignado a una tipología o a otra (Corpas Pastor 1996, García-Page 2008). Además, la posibilidad de trasvase de unidades de una clase a otra es un fenómeno que complica enormemente esta labor de clasificación (Penadés Martínez 2012). Nos interesa, en este punto, establecer el criterio clave que consideramos a la hora de delimitar las categorías de las fórmulas y las locuciones, unidades de las que nos ocupamos en este trabajo, como precisamos más adelante. A partir de la definición que hemos adoptado para la clase de locución, basada en los criterios formal (fijación), semántico y sintáctico, adoptamos este último para diferenciar este tipo de unidad de las fórmulas. Así, una unidad puede ser asignada a la clase de las locuciones siempre que pueda corresponder a una clase de palabra y, en consonancia con esta, pueda desempeñar una función gramatical y sintáctica concretas dentro de una oración. Como podemos ver, este criterio es coherente con el enfoque teórico seguido y permite identificar los diferentes tipos de locución. Asimismo, no sería posible basarnos únicamente en el rasgo de autonomía, comúnmente atribuido a las fórmulas, como elemento diferenciador dado que, como ya se ha demostrado, solo algunos tipos de fórmulas gozan de esta cualidad (Núñez Bayo 2016). De esta manera, no sirve como criterio básico y general para distinguir fórmulas y locuciones. En cambio, el criterio sintáctico indicado sí puede aplicarse sin restricciones ${ }^{5}$.

\footnotetext{
5 Sobrepasaría enormemente los objetivos de este trabajo la consideración de las diferentes cuestiones que atañen a la separación entre fórmulas y locuciones. Sin embargo, nos parece conveniente destacar uno de los problemas que surgen a raíz de la dificultad de delimitar clases de unidades como estas: la proliferación de denominaciones
} 
Por último, en relación con el principio diferenciador adoptado, hemos de recordar que, como señala Penadés Martínez (2017: 69-75), las locuciones, al igual que las palabras, pueden organizarse en clases o categorías de acuerdo con sus propiedades combinatorias y en función de la información morfológica que pueden proporcionar. Estas unidades, de este modo, "por sus particularidades morfológicas, combinatorias y designativas o denotativas" (Penadés Martínez 2017: 69), pueden ser agrupadas en las siguientes clases: locuciones nominales, adjetivas, pronominales, verbales, adverbiales, prepositivas y conjuntivas ${ }^{6}$.

\subsection{Estudios de fraseología judeoespañola}

Puede decirse que la fraseología judeoespañola es un terreno prácticamente inexplorado. Ello no significa que no haya habido interés por el componente fraseológico de esta variedad, sino que el interés se ha focalizado en una clase concreta de UF: los proverbios y refranes, a condición de que se les considere UF, y se ha orientado fundamentalmente a su recopilación e integración en diferentes obras lexicográficas. No se han realizado estudios fraseológicos desde el punto de vista de la Fraseología como subdisciplina lingüística.

terminológicas que se refieren a fraseologismos muy parecidos entre sí. Así, muchas de las unidades que se recogen bajo los términos locuciones discursivas (Zamora Muñoz 1998), locuciones marcadoras (Ruiz Gurillo 1998, Montoro del Arco 2006) o locuciones oracionales (García-Page 2008) podrían corresponder a diferentes tipos de fórmulas (y, en este caso, estarían más próximas, sobre todo, a las llamadas fórmulas discursivas (Núñez Bayo 2016)). Como ya habíamos señalado, diferentes puntos de vista respecto al mismo objeto de estudio pueden dar resultados heteregéneos e, incluso, dispares.

6 Montoro del Arco (2006) incluye estas dos últimas clases de locución en una categoría general, la de las locuciones particulares — por su relación con la noción de "partícula"-, junto con otra clase más, la de las locuciones marcadoras. No consideramos esta última categoría, puesto que, como ya hemos señalado, este tipo de locución puede entenderse como un tipo de fórmula, de acuerdo con el enfoque que hemos adoptado. En este sentido, tampoco consideramos un tipo de locución las llamadas locuciones interjectivas, puesto que, como ya se ha demostrado, las unidades que suelen adscribirse a esta clase son, asimismo, fórmulas (Zuluaga 1980, Corpas Pastor 1996, Penadés Martínez 2006). 
Hay que señalar que las recopilaciones de refranes y otros fenómenos fraseológicos judeoespañoles se producen desde bastante pronto en la Lexicografía hispánica. Así, Scandola (2003: 363) nos habla del Libro de refranes copilado por el orden del a.b.c. en el que se contiene quatro mil y trescientos refranes. El mas copioso que hasta oy ha salido impresso, de Pedro Vellés (1549) que contiene 67 refranes sefardíes. Asimismo, según Sevilla Muñoz y Sevilla Muñoz (2000: 201-202), en 1888, aparece el libro Proverbes judéo-espagnols, en el que Kayserling ordena y anota 759 de las paremias recogidas en Budapest, Belgrado y Roustchouck (la actual Ruse, en Bulgaria). Casi diez años más tarde, en 1897, el mismo autor incluirá más refranes sefardíes en el artículo "Quelques proverbes judéo-espagnols", aunque ya, en 1890, había publicado su Biblioteca española-portugueza-judaica, donde igualmente encontramos mucho material paremiológico. En el siglo XX, destaca la recopilación y estudio en lengua inglesa de Levy (1969), la colección de Saporta y Beja (1978), Refranes de los judios sefardies y otras locuciones típicas de los judios sefardies de Salónica y otros sitios de Oriente y los trabajos de Carracedo y Romero Castelló (1981), Nezirovic (1992) y Romero (2001). Por supuesto, tampoco podemos olvidar los diccionarios clásicos de judeoespañol; esto es, Romano (1933) y Nehama (1977), que incluyen en sus páginas fraseologismos, aunque sea de manera esporádica. Igualmente, cabe mencionar el Diccionario Akal del refranero sefardí de Cantera Ortiz de Urbina (2004). No obstante, aparte de esta labor recopilatoria, encontramos muy poco material bibliográfico relacionado con el análisis lingüístico de la fraseología; antes bien, hallamos estudios culturales o antropológicos como los de Cantera Ortiz de Urbina (1997; 2002) y August-Zarebska (2011). Por lo que se refiere a la clasificación y análisis de UF del judeoespañol a partir de las categorías

\footnotetext{
7 Y ello, a pesar de que, desde el 2000, en el ámbito de la filología hispánica, se han hecho grandes avances en la investigación fraseológica (incluida la fraseología especializada) desde la perspectiva diacrónica en los que podrían incardinarse los estudios de fraseología judeoespañola. Pueden mencionarse, entre otros, los más recientes trabajos de Echenique Elizondo et al. (eds.) (2016, 2017 y 2018), Montoro del Arco (2017) y Tabares Plasencia (2018 y 2020).
} 
de la moderna Fraseología española, solo nos consta la presencia de un trabajo de Quintana (2011), que aplica a los fraseologismos relacionados con el sexo en la lengua coloquial de Bursa (Turquía) las clases propuestas por Corpas (1996), de una contribución de Bürki (2006) que examina cuál es el papel de las UF en la prensa judeoespañola del siglo XX, y un apartado de la tesis doctoral de Álvarez López (2017: 164-174) sobre la revista sefardí Aki Yerushalayim.

\section{Marco metodológico}

En diferentes partes de la obra de Papo, encontramos numerosos ejemplos de colocaciones, locuciones, fórmulas, así como una gran cantidad de otros tipos de unidades pluriverbales que podrían, asimismo, considerarse fraseologismos, aunque no suelan clasificarse como tales. En este trabajo, por cuestiones de espacio, nos centramos en el examen de las fórmulas y locuciones. Pero antes, hablaremos someramente de la obra objeto de investigación y del procedimiento para la extracción y análisis de la UF.

\subsection{La obra objeto de análisis}

La obra objeto de análisis se publicó en Viena en el último cuarto del siglo XIX; se encuentra escrita en judeoespañol y alemán, en alfabeto hebreo con escritura rasí. Precisamente, este último hecho es el que nos ha animado a realizar una edición transcrita ${ }^{8}$ y comentada de la misma?.

\footnotetext{
8 Como se indica en Hernández Socas, Sinner y Tabares Plasencia (2010: 334, nota 2), se ha utilizado para la transcripción de este texto aljamiado el sistema ideado por Hassán (1978), que, sin embargo, se ha debido adaptar, en ocasiones, a las características específicas de la obra, dado que no solo contiene texto en romance, sino en alemán, lengua para la que, en principio, no se había planteado la escritura rasí. Este hecho es puesto en evidencia incluso por Papo (1884: III) cuando habla de las dificultades de reproducir en este tipo de escritura la lengua alemana. Este sistema de transcripción será presentado de forma sistemática en la edición de esta obra que están preparando Sinner, Tabares Plasencia y Hernández Socas.

9 Para más detalles sobre el autor la obra, remitimos a Hernández Socas, Sinner y Tabares Plasencia (2010).
} 
En cuanto a su estructura y contenido, sin entrar en pormenores para los que se remite a Hernández Socas, Sinner y Tabares Plasencia (2010), la obra consta de 112 páginas (96 numeradas en arábigos y 16 en romanos). En las 16 primeras páginas, se recoge, en primer lugar, lo que constituye una especie de "guía de uso", donde Papo informa al lector de las decisiones que ha tomado para la adecuación al alfabeto hebreo de determinados fenómenos fónicos y gráficos del alemán. Asimismo, ofrece unos apuntes de gramática alemana (artículo, pronombres, tiempos verbales ${ }^{10}$, orden de palabras, etc.), así como el índice de contenidos que se inician en las páginas numeradas en arábigos. Estas últimas se dividen en tres partes principales (dos de ellas de carácter lingüístico) y un anexo: la primera (pp. 1-49), estructurada en ocho capítulos, donde se recoge el léxico más "usual” en alemán, de acuerdo con su categoría gramatical. El más amplio de los capítulos de la primera parte es el dedicado a los sustantivos, donde, a su vez, se efectúan subdivisiones por campos semánticos. En la segunda parte (pp. 51-78) se presentan diferentes situaciones comunicativas a las que el viajero tendría que enfrentarse durante su estancia en tierras germánicas. En la tercera parte, sin carácter lingüístico (pp. 79-88), se recoge información y recomendaciones de utilidad al viajero (documentación necesaria, moneda, medios de transporte locales, etc.) y una suerte de "guía turística" sobre la ciudad de Viena. Por último, en el anexo (pp. 89-96) se consignan unas tablas alfabéticas con el léxico utilizado en la obra que requería de aclaración por parte del autor. En las partes lingüísticas, Papo comienza formalmente siempre con el judeoespañol para, acto seguido, ofrecer la correspondencia en alemán de todas las unidades tanto mono como pluriverbales que se hallan en nuestra obra.

10 En relación al tratamiento dispensado por Papo a los tiempos verbales en El Trajumán, remitimos a Tabares Plasencia, Sinner y Hernández Socas (2012). 


\subsection{Procedimiento de extracción y análisis}

El proceso de extracción y análisis de las UF se ha desarrollado en cinco fases sucesivas, a saber:

a) Lectura atenta y examen exhaustivo de la edición transcrita de la obra;

b) Identificación y vaciado de las unidades pluriverbales encontradas en el texto;

c) Análisis lingüístico de las unidades recogidas, a fin de identificar su tipología;

d) Búsqueda de las unidades recolectadas y de sus equivalentes en español de España actual en diccionarios y corpus de referencia;

e) Tratamiento del material recogido a partir de criterios lexicográficos o fraseográficos.

El primer paso para extraer los diferentes ejemplos de fraseologismos de El Trajumán consistió en la realización de una lectura atenta de la obra transcrita, a fin de identificar aquellas unidades que podrían considerarse UF, ya fuera por sus características formales ya fuera por la función que cumplían en el texto. Como hemos señalado, hemos optado por centrarnos inicialmente en la recolección y análisis de dos tipos de UF, las fórmulas y las locuciones, dado que eran las clases mejor representadas en el texto.

De este modo, teniendo en cuenta, por un lado, este modelo definitorio y, basándonos, por otro lado, en el análisis del contexto en el que aparecía cada unidad, hemos elaborado una primera propuesta de clasificación de las unidades recolectadas y las hemos repartido en dos grandes grupos: fórmulas y locuciones. A partir de ahí, hemos procedido a la ordenación de las locuciones en diferentes clases, a saber: nominales, adjetivas, pronominales, verbales, adverbiales, prepositivas y conjuntivas. En la labor de identificación y clasificación de las unidades, nos hemos apoyado en diferentes fuentes, como corpus, textos teóricos y diccionarios. De esta manera, hemos querido asegurarnos de que todas las unidades fraseológicas recolectadas podrían considerarse fraseologismos. 
Es importante resaltar que en el proceso de análisis lingüístico de las unidades recogidas hemos adoptado una perspectiva intralingüística tomando como referente el español de España actual. Por ello, además de catalogar las unidades encontradas, hemos buscado establecer sus posibles equivalentes lingüísticos. Para llevar a cabo esta tarea, nos hemos basado, fundamentalmente, en la información lexicográfica proporcionada por el Diccionario fraseológico documentado del español actual (DFDEA) (Seco, Andrés y Ramos 2017). Cuando esta obra no recogía el posible equivalente, hemos utilizado otras fuentes lexicográficas, como el Diccionario de la lengua española (DLE) (Real Academia Española y Asociación de Academias de la Lengua Española, en línea); el Diccionario fraseológico del español moderno (Varela y Kubarth 1994); el Diccionario de uso del español (Moliner 1996) y el Diccionario de refranes, adagios, proverbios, modismos, locuciones y frases proverbiales de la lengua española (Sbarbi 1922). En todos los casos, hemos contrastado la información recogida con datos extraídos del Corpus Diacrónico del Español (CORDE), de la Real Academia Española. Asimismo, hemos consultado otras fuentes, como el Corpus Histórico Judeoespañol (CORHIJE) (García Moreno en línea), el Diccionario Histórico del Judeoespañol (DHJE) (García Moreno y Pueyo Mena en línea) y el Diccionario crítico etimológico castellano e hispánico (Corominas y Pascual 1980), para obtener información sobre aquellas UF que no tenían equivalentes en español. Pongamos como ejemplo de nuestra forma de proceder la locución empleada por Papo En ancho: 


\section{Tabla 1. Ejemplo sin equivalente en español: en ancho}

\begin{tabular}{|c|c|c|c|c|c|}
\hline Contexto & $\begin{array}{l}\text { Ubicación } \\
\text { en el texto }\end{array}$ & $\begin{array}{l}\text { Propuesta de } \\
\text { clasificación }\end{array}$ & $\begin{array}{l}\text { Propuesta } \\
\text { de forma } \\
\text { canónica }\end{array}$ & $\begin{array}{l}\text { Propuesta de } \\
\text { definición }\end{array}$ & Comentarios \\
\hline $\begin{array}{l}\text { Tavla de } \\
\text { palavras } \\
\text { poco } \\
\text { conocịdas, } \\
\text { declaradas } \\
\text { más en ancho, } \\
\text { a_la regla } \\
\text { álef-bet (p. XI) }\end{array}$ & $\begin{array}{l}\text { "Nota” } \\
\text { (Índice) }\end{array}$ & $\begin{array}{l}\text { Loc. } \\
\text { adverbial }\end{array}$ & En ancho & $\begin{array}{l}\text { 'En detalle, } \\
\text { más detalla- } \\
\text { damente' }\end{array}$ & $\begin{array}{l}\text { En Corominas } \\
\text { (s.v.): el } \\
\text { vocablo ancho } \\
\text { se relaciona } \\
\text { con amplio; } \\
\text { cultismo, hacia } \\
1640\end{array}$ \\
\hline
\end{tabular}

Finalmente, a fin de establecer las bases para el tratamiento lexicográfico o fraseográfico de las UF, hemos buscado proporcionar su forma canónica y una definición de cada una de ellas. Las locuciones verbales presentadas en esta tabla ilustran el resultado de la labor llevada a cabo:

\section{Tabla 2. Ejemplos de locuciones verbales para su comparación con el español europeo actual}

\begin{tabular}{|c|c|c|c|c|c|c|}
\hline Unidad & Contexto & $\begin{array}{l}\text { Ubicación } \\
\text { en el texto }\end{array}$ & $\begin{array}{l}\text { Clasifi- } \\
\text { cación }\end{array}$ & $\begin{array}{l}\text { Correspon- } \\
\text { diente }\end{array}$ & Acepción & Comentarios \\
\hline $\begin{array}{l}\text { dar la } \\
\text { en-buëna- } \\
\text { hora }\end{array}$ & $\begin{array}{l}\text { dar la } \\
\text { en-buëna-hora, } \\
\text { glückwünschen, } \\
\text { begrüs[s]en (36) }\end{array}$ & $\begin{array}{l}\text { "IV. } \\
\text { Verbos" }\end{array}$ & $\begin{array}{l}\text { Loc. } \\
\text { verbal }\end{array}$ & $\begin{array}{l}\text { Darla } \\
\text { enborabuena }\end{array}$ & $\begin{array}{l}\text { [a alguien] } \\
\text { 'Felicitar[le]'. } \\
\text { (DFDEA, p. } \\
365 \text { ) }\end{array}$ & $\begin{array}{l}\text { Forma léxica: } \\
\text { en-buëna-hora / } \\
\text { enhorabuena. }\end{array}$ \\
\hline $\begin{array}{l}{[\mathrm{H}] \text { aćer }} \\
\text { de ụn } \\
\text { camịno } \\
\text { dos } \\
\text { mandados }\end{array}$ & $\begin{array}{l}\text { [b]aćer de ụn } \\
\text { camịno dos } \\
\text { mandados, zwei } \\
\text { Flị[e]gen mị } \\
\text { einer Klap[p]e } \\
\text { schlagen (47) }\end{array}$ & $\begin{array}{l}\text { "Algo } \\
\text { del estịlo } \\
\text { (modo) } \\
\text { del avlar" }\end{array}$ & $\begin{array}{l}\text { Loc. } \\
\text { verbal }\end{array}$ & $\begin{array}{l}\text { Hacer de un } \\
\text { camino dos } \\
\text { mandados }\end{array}$ & $\begin{array}{l}\text { 'Se dice } \\
\text { del que } \\
\text { aprovecha la } \\
\text { oportunidad } \\
\text { de hacer } \\
\text { algún } \\
\text { encargo para } \\
\text { desempeñar } \\
\text { juntamente } \\
\text { otro'. (Sbarbi, } \\
\text { p. 165) }\end{array}$ & \\
\hline $\begin{array}{l}{[\mathrm{H}] \text { aćer }} \\
\text { del bovo }\end{array}$ & $\begin{array}{l}\text { [b]aćer } \\
\text { del bovo, } \\
\text { sịchdụm }[\mathrm{m}] \\
\text { stel[1]en }(47)\end{array}$ & $\begin{array}{l}\text { "Algo } \\
\text { del estịlo } \\
\text { (modo) } \\
\text { del avlar" }\end{array}$ & $\begin{array}{l}\text { Loc. } \\
\text { verbal }\end{array}$ & $\begin{array}{l}\text { Hacerse el } \\
\text { bobo }\end{array}$ & $\begin{array}{l}\text { 'Hacerse el } \\
\text { tonto'. (DLE, } \\
\text { s.v. bobo) }\end{array}$ & \\
\hline
\end{tabular}




\section{Resultados}

En el vaciado llevado a cabo, hemos contabilizado 216 UF, fundamentalmente, fórmulas y locuciones, de acuerdo con nuestra propuesta de clasificación. En este cómputo, las locuciones adverbiales son el tipo de fraseologismo más frecuente en el texto (102), seguido de las fórmulas (42) y las locuciones verbales (28). En el siguiente gráfico (Gráfico 1), podemos ver los tipos de UF encontradas:

\section{Gráfico 1. Tipos y número de UF en El Trajumán}

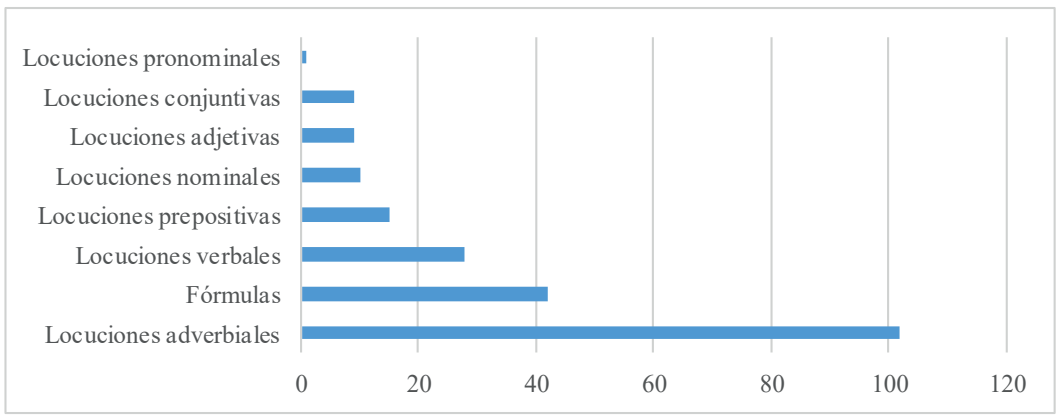

Las fórmulas y locuciones registradas se localizan en diferentes apartados a lo largo de todo el libro. Conviene, sin embargo, establecer una distinción formal entre dos maneras de registro: por una parte, están aquellos fraseologismos empleados por el autor en la redacción de partes del libro que aportan información sobre la obra en sí. Estas unidades se insertan, por tanto, en contextos determinados, por lo que es posible identificar fácilmente qué funciones cumplen dentro del texto (la cursiva es nuestra en todos los ejemplos marcados):

(1) $[\mathrm{H}]$ ay tiempo, que muchos señores del Oriente viajantes por la Nemŝia, deśean un livrico semejante por darsen algo a entender. Y aun_que es muy difícil (fuerte) de conponerlo, tanto de parte del español que está mezclado en cada provincia 
de la Turquía con la [h]avla de aquel país, como también de parte del alemano (nemŝesco) que no se puede pronunciar cumplidamente con la letra ladina (raší), con todo reśolve por inĝeniarlo con procurar de reformar todo lo posible por que sea entendido ("Al leedor (meldador)", p. III).

Por otra parte, se encuentran aquellas unidades que figuran como "ejemplos", es decir, constituyen muestras lingüísticas presentadas por el autor, y que se insertan, en la gran mayoría de las veces, en contextos muy breves. Estas unidades aparecen:

a) en los listados de "palabras más usuales" para hablar en alemán, donde figuran ordenadas de acuerdo con la categoría gramatical a la que pertenecen:

(2) Nombres sustantivos.

3. Del tiempo. Von der Zeịt.

ụn dịa, eịn Tag

dịa de fiesta, Fest-Tag (p. 5).

b) en el repertorio de las diferentes situaciones comunicativas presentadas en el texto:

(3) Converśación

Bụenos dịas tenga sụ”me. Señor, señora, señorịta. Gụten Tag, meịn Herr, meine Dame, meịn Fräuleịn (p. 55).

c) en las recomendaciones que hace Papo a los viajeros:

(4) Por atención

Se gụarden los se" vịajantes de cierta ĝente que se les demostran veluntariamente plaćenteros y no tienen buẹna entịnción (p. 83).

Esto se refleja en el siguiente gráfico (Gráfico 2), donde podemos ver cómo la mayoría de los fraseologismos recopilados se localizan en los listados de palabras y en los apartados que recogen situaciones comunicativas: 
Gráfico 2. Distribución de fraseologismos en El Trajumán

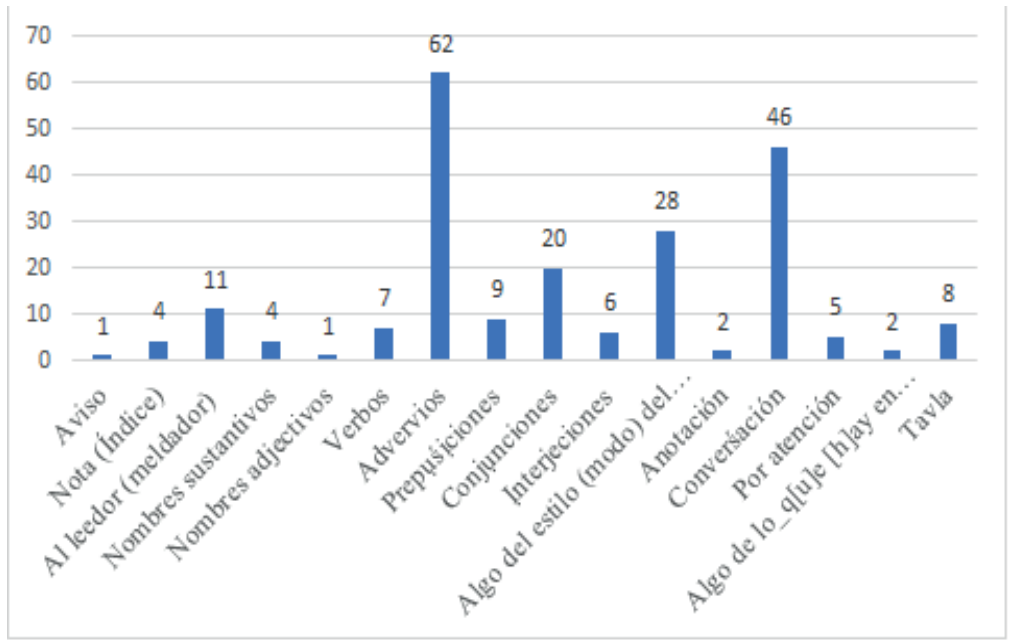

Al revisar el tratamiento que da el autor a estas unidades léxicas llama la atención la forma y la ubicación donde se registran, puesto que, por lo general, Papo ha procedido coherentemente a la hora de organizarlas. Vemos, de este modo, que la gran mayoría de las fórmulas aparecen recogidas en el apartado dedicado a las "Interjecciones", clase de palabras generalmente relacionada con este tipo de unidad, y en los apartados en los que se presentan situaciones comunicativas diversas, a saber: "Algo del estịlo (modo) del avlar" y "Converśación” (esto es, en situaciones de habla donde estos fraseologismos naturalmente aparecen). Véase gráfico 3: 


\section{Gráfico 3. Ubicación de las fórmulas en El Trajumán}

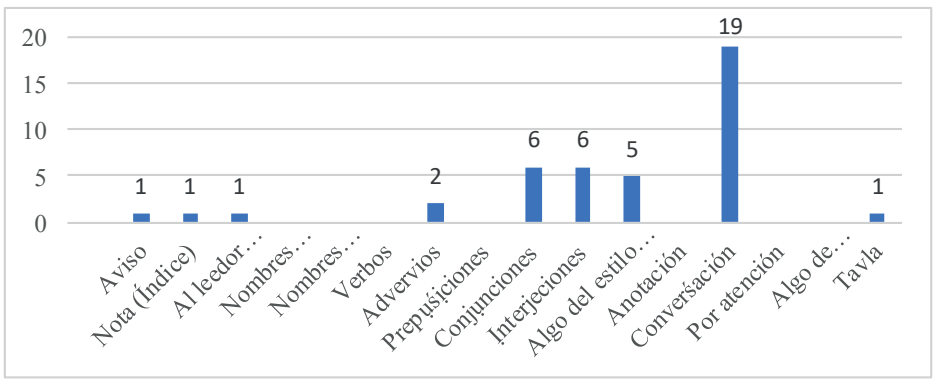

De igual manera, como se puede observar en el gráfico 4, la gran mayoría de las locuciones adverbiales se registran en el apartado dedicado a los “adverbios y frases adverbiales":

Gráfico 4. Ubicación de las locuciones adverbiales en El Trajumán

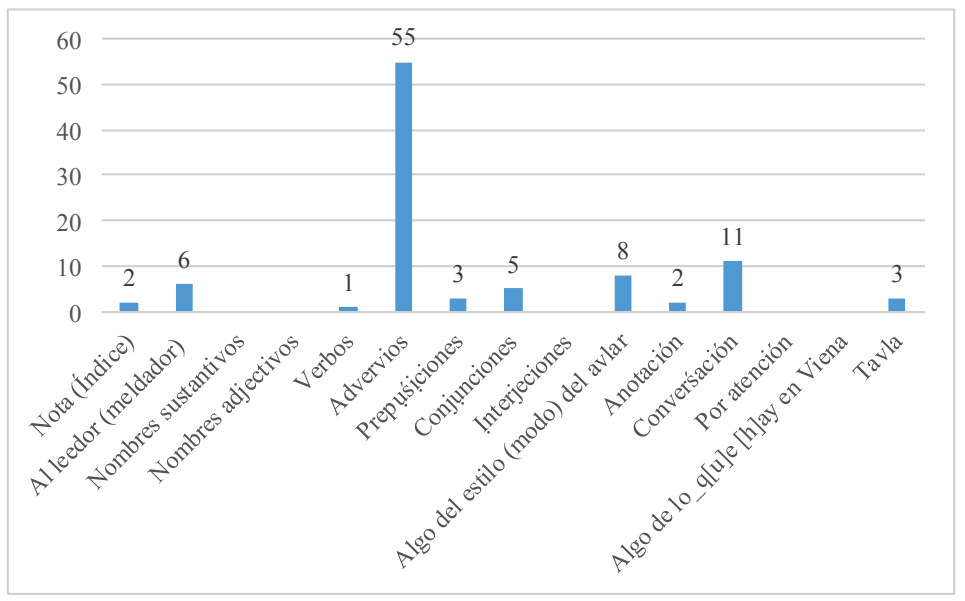

Nos ha parecido digno de nota, asimismo, el hecho de que el autor, en el apartado destinado a los “verbos”, presente no solo unidades léxicas simples sino también ejemplos de locuciones verbales y un número relevante de colocaciones verbales, como podemos ver en esta pequeña muestra, en la que la primera y la tercera unidades 
son ejemplos de colocaciones verbales ${ }^{11}$ y la segunda y la última, de locuciones verbales.

(5) [b]aćer cośquillas, kịtzeln amar querer (bien), lị[e]ben [b]aćer una corteśị, einen Dị[e]ner machen echar en cara, einen Vorwụrf machen (p. 35).

Merece especial atención el apartado "Algo del estịlo (modo) del avlar”, puesto que la inmensa mayoría de las unidades léxicas que lo componen constituyen fraseologismos, como podemos ver en esta pequeña muestra de unidades incluidas en esta sección:

(6) dar en prenda, als Pfand versetzen.

comer a tente bonete, einen gụten Tịsch fü[h]ren. (...) va en ello mi [h]onor, meine E[h]re ste[h]t aụf dem Spị[e]le. (...)

de un cavo al otro, von Anfang bịs zụ Ende. (...) apụëstas (metes al baš) 2 florịnes)? wịl[1]st dụ ụm 2 Gụlden wetten? (...)

estava para caer, er wịrd bald gefallen (p. 48).

En este fragmento, los fraseologismos destacados constituyen ejemplos de locuciones adverbiales (en prenda - que, en este ejemplo en concreto integra una colocación compleja (Koike 2001; Penadés Martínez 2017): dar en prenda; a tente bonete y de un cavo al otro); fórmula (va en ello mi honor), colocación (metes al baš) y locución verbal (estaba para caer).

\footnotetext{
11 Para algunos autores, las unidades que identificamos aquí como ejemplos de colocaciones constituyen, en realidad, construcciones con verbos de soporte o de apoyo (Alonso Ramos 2004, Sanromán Vilas 2014). Sin embargo, para otros, como Koike (2011), estas construcciones con verbo soporte son colocaciones funcionales simples ("formadas por un verbo y un SN (sintagma nominal), en las que el verbo funciona como verbo soporte y el significado léxico se concentra en el sustantivo núcleo del SN. El verbo soporte, llamado también verbo ligero o de apoyo, se caracteriza por no mantener su significado léxico y habilita al sustantivo para que el conjunto funcione como un verbo complejo" (Koike 2011: 3).
} 
Otra cuestión de indudable interés atañe a las glosas que introduce el autor al presentar determinados fraseologismos. En los ejemplos que siguen, podemos apreciar el empleo de estas glosas en la presentación de las diferentes unidades fraseológicas registradas:

(7) en cuanto (tocante), was betrịf[f]t ("VI. Prepuśiciones", p. 45). no lo [h]ịce de ịntento (maksụs), ịch habe es nicht absịchtlịch gemacht (“Algo del estịlo (modo) del avlar”, p. 48).

[H]ágame sụ" me el favor (tenga la bondad) de darme la carta. Haben Sị[e] dị[e] Gụ̣"te, mịr den Brị[e]f zu Geben (“Conversación”, p. 59). Conversación”, p. 66). sịn duda: sịn dubio" ("Tavla”, p. 92).

En esta muestra, identificamos un ejemplo de locución prepositiva (en cuanto); algunas locuciones adverbiales (de intento, de propina y sin duda); una fórmula (H]ágame sụ"me el favor) y una locución adjetiva (de casa).

Como hemos mencionado al principio, El Trajumán encierra diversos aspectos de interés lingüístico y, entre ellos, destaca, exactamente, el uso profuso de glosas metalingüísticas con fines variados (Sinner, Hernández Socas y Tabares Plasencia 2014b). De acuerdo con los editores de la obra, este uso se justifica por el género textual en el que se inserta el libro, así como por la finalidad didáctica que claramente persigue su autor y su intención de llegar a lectores sefardíes procedentes de las más diversas regiones. La enorme variación dialectal que caracteriza al judeoespañol en general, y, en concreto, al de Viena, en cuya conformación las lenguas en contacto han desempeñado un papel crucial, explican también en buena medida el elevado número de glosas que encontramos en la obra.

En el caso específico de las glosas empleadas en la presentación de los fraseologismos o de la inclusión de estas unidades como glosas, cabe investigar qué papel desempeñan: ¿Introducen variantes sinonímicas?, ¿se trataría de geosinónimos?, ¿explican o aclaran palabras que podrían ser desconocidas para el lector? Por ahora, podemos decir que estas cuestiones serán objeto de un 
estudio posterior, en el que reflexionaremos, a partir de las categorías establecidas por Sinner, Hernández Socas y Tabares Plasencia (2014b), sobre el uso de las glosas identificadas junto a la información fraseológica recabada.

Como hemos señalado, del análisis de las UF extraídas de la obra, hemos podido establecer una propuesta inicial de clasificación: cada unidad ha sido asignada a una clase específica, siguiendo las directrices propuestas en la teoría fraseológica actual. En el desarrollo de esta propuesta, hemos tenido en cuenta, además, el papel que desempeñaba la UF en el texto, y hemos considerado la información lexicográfica y de corpus que hemos podido obtener de cada una de ellas.

Asimismo, el análisis de estas unidades muestra la importancia de tomar en consideración otras lenguas, además del español, puesto que hemos identificado en algunas de ellas la presencia de extranjerismos. Esto no es algo inusual, dado que es muy común encontrar en los textos escritos en judeoespañol numerosos elementos foráneos, tales como turquismos, galicismos, eslavismos o hebraísmos. Así pues, en el ejemplo 8, mǔš puede ser un italianismo (musso), según el Diccionario histórico judeoespañol, o un helenismo, de acuerdo con Nehama (1977: 375) (donde se recoge la voz mušo 'lèvre, lippe' como procedente del griego popular $\mu$ ovooú $\delta \alpha$ y del bajo latín, de acuerdo con Sinner, Hernández Socas y Tabares Plasencia $(2014 b)$ :

(8) meter el mụšo en todo, sịch ịn allem mịschen (“Algo del estịlo (modo) del avlar”, p. 47).

También de acuerdo con estos investigadores, la palabra bǎs, que aparece en el siguiente fraseologismo, podría ser un turquismo, ya que la palabra correspondiente en turco es babis o babe:

(9) apụëstas (metes al baš) 2 florịnes)? (“Algo del estịlo (modo) del avlar”, p. 48). 
En el proceso de análisis y clasificación de las unidades recopiladas, hemos encontrado obstáculos de diferente índole y queremos destacar aquí dos de ellos, uno de carácter específico y otro de carácter general: el primero tiene que ver con la dificultad de asignar a algunas locuciones, como la que aparece en la tabla 3 , una clase única, dado que este tipo de unidad puede ser considerada tanto locución adjetiva como adverbial, según el contexto en el que aparezcan:

\section{Tabla 3. Ejemplo de locución con problemas de asignación a una clase gramatical}

\begin{tabular}{lllll}
\hline Contexto & $\begin{array}{l}\text { Ubicación en el } \\
\text { texto }\end{array}$ & $\begin{array}{l}\text { Propuesta de } \\
\text { clasificación }\end{array}$ & $\begin{array}{l}\text { Propuesta de } \\
\text { forma canónica }\end{array}$ & $\begin{array}{l}\text { Propuesta de } \\
\text { definición }\end{array}$ \\
\hline $\begin{array}{l}\text { de burla, } \\
\text { aụs Spaß } \\
(44)\end{array}$ & $\begin{array}{l}\text { "V. Adverbios } \\
\text { y frases } \\
\text { adverbiales" }\end{array}$ & $\begin{array}{l}\text { Loc. adverbial } \\
\text { Loc. Adjetiva }\end{array}$ & De burla & 'Con \\
& & & $\begin{array}{l}\text { intención de } \\
\text { hacer reír o } \\
\text { sin seriedad' }\end{array}$ \\
\hline
\end{tabular}

Sin embargo, una gran parte de las unidades de este tipo aparece en listados o en situaciones comunicativas brevemente descritas, por lo que, tal y como hemos apuntado, se insertan en contextos demasiado breves, y esto no nos permite tomar una decisión acerca de su estatus a partir del análisis contextual. En estos casos, hemos decidido incluir estas unidades en ambas clases, indicando la posibilidad de que puedan clasificarse o definirse de dos formas.

El segundo y quizá más importante obstáculo encontrado concierne a la ausencia de estudios acerca de fraseología del judeoespañol. Por lo que hemos podido comprobar, esta no ha sido objeto de una investigación sistemática y rigurosa. Este hecho entorpece enormemente el estudio de aquellas unidades que parecen ser propias del judeoespañol y carecen de equivalentes conocidos. Hemos intentado subsanar este problema de dos formas: por un lado, intentando localizar ejemplos de uso de estas unidades o ejemplos de unidades similares en el CORHIJE. Por otro lado, de forma paralela, hemos realizado búsquedas en el DHJE, con el objetivo de recoger información sobre algunos de los elementos que componen 
estas unidades y, de esta manera, buscar pistas que nos ayuden a establecer su forma y definición.

En la primera imagen (Figura 1), extraída del citado CORHIJE, vemos el resultado de la búsqueda para la palabra delantre. En este caso, nuestro objetivo es determinar si la expresión recogida en Papo puede considerarse un fraseologismo y, siendo así, si su forma canónica es por dịa en delantre o en delantre. Ya en la segunda imagen (Figura 2), sacada del DHJE, podemos ver la información obtenida acerca del vocablo mušo, que aparece en la unidad meter el $m u \check{s} O$, a la que hemos hecho referencia con anterioridad:

\section{Conclusiones}

Con esta contribución iniciamos un camino hasta ahora apenas transitado en la investigación sobre el judeoespañol: la aplicación de la teoría fraseológica moderna y del trabajo de corpus a su estudio. Para ello, hemos llevado a cabo la labor de extracción, sistematización y clasificación de todas las UF de la obra aunando diversos enfoques teóricos (Corpas Pastor 1996, Penadés Martínez 2012, López Simó 2016, Núñez Bayo 2016) y valiéndonos de las herramientas proporcionadas por la lingüística de corpus. A su vez, y a diferencia de otros trabajos sobre el judeoespañol, hemos querido poner en relación las UF encontradas con aquellas paralelas en el español general. Esto implica que partimos de la consideración teórica del judeoespañol como variedad en el seno del español, cuya comparación consideramos reveladora de la necesidad de no perder de vista esta relación entre ambas variedades.

Aunque este artículo abre un nuevo camino, también señala los frentes abiertos que requieren atención para futuras investigaciones. La cuestión de las glosas metalingüísticas, de la identificación de las colocaciones o de la carencia de estudios sobre la fraseología del judeoespañol, señalados previamente, son ejemplos de ello. Asimismo, hemos de hacer referencia a dos cuestiones más que este trabajo ha permitido poner en evidencia: 


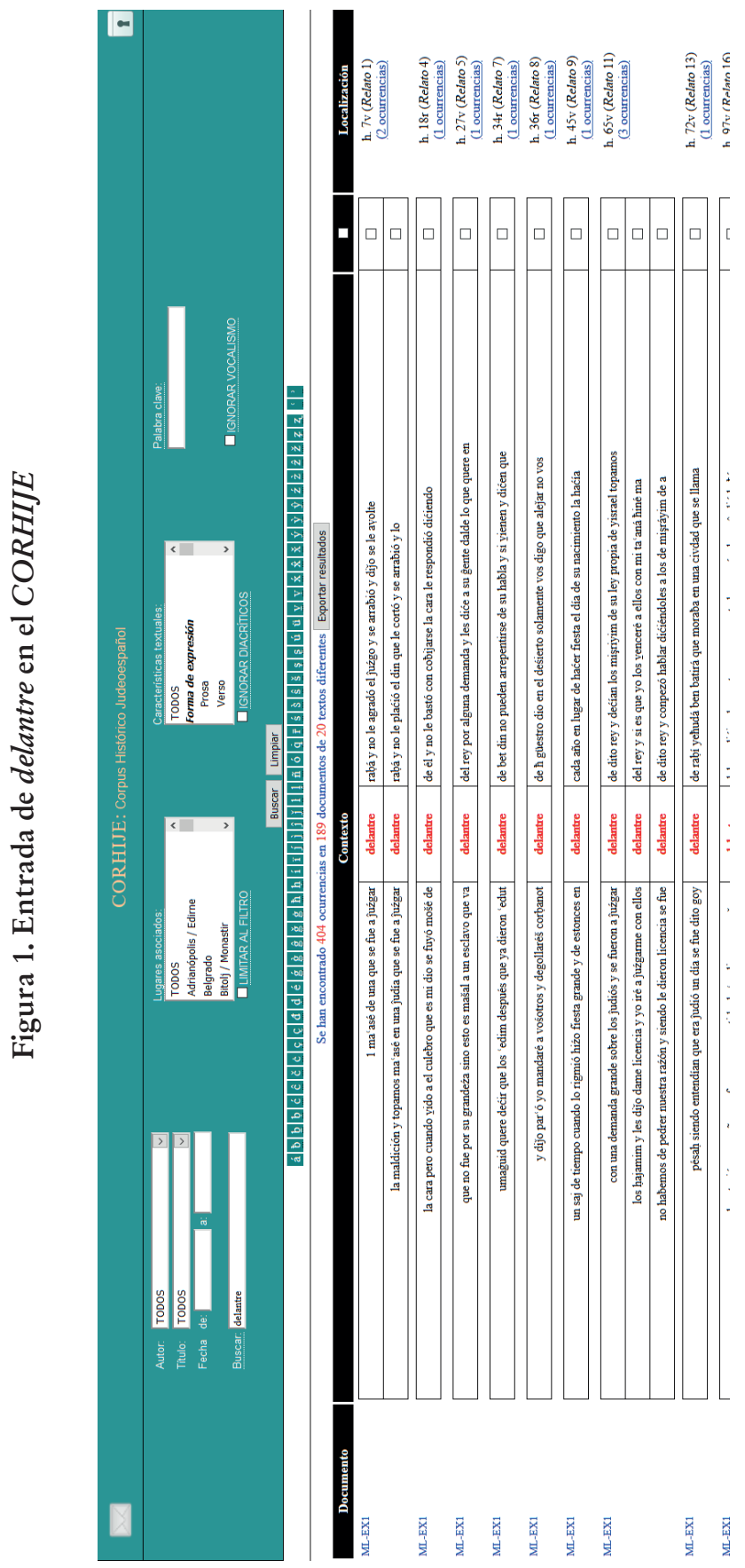




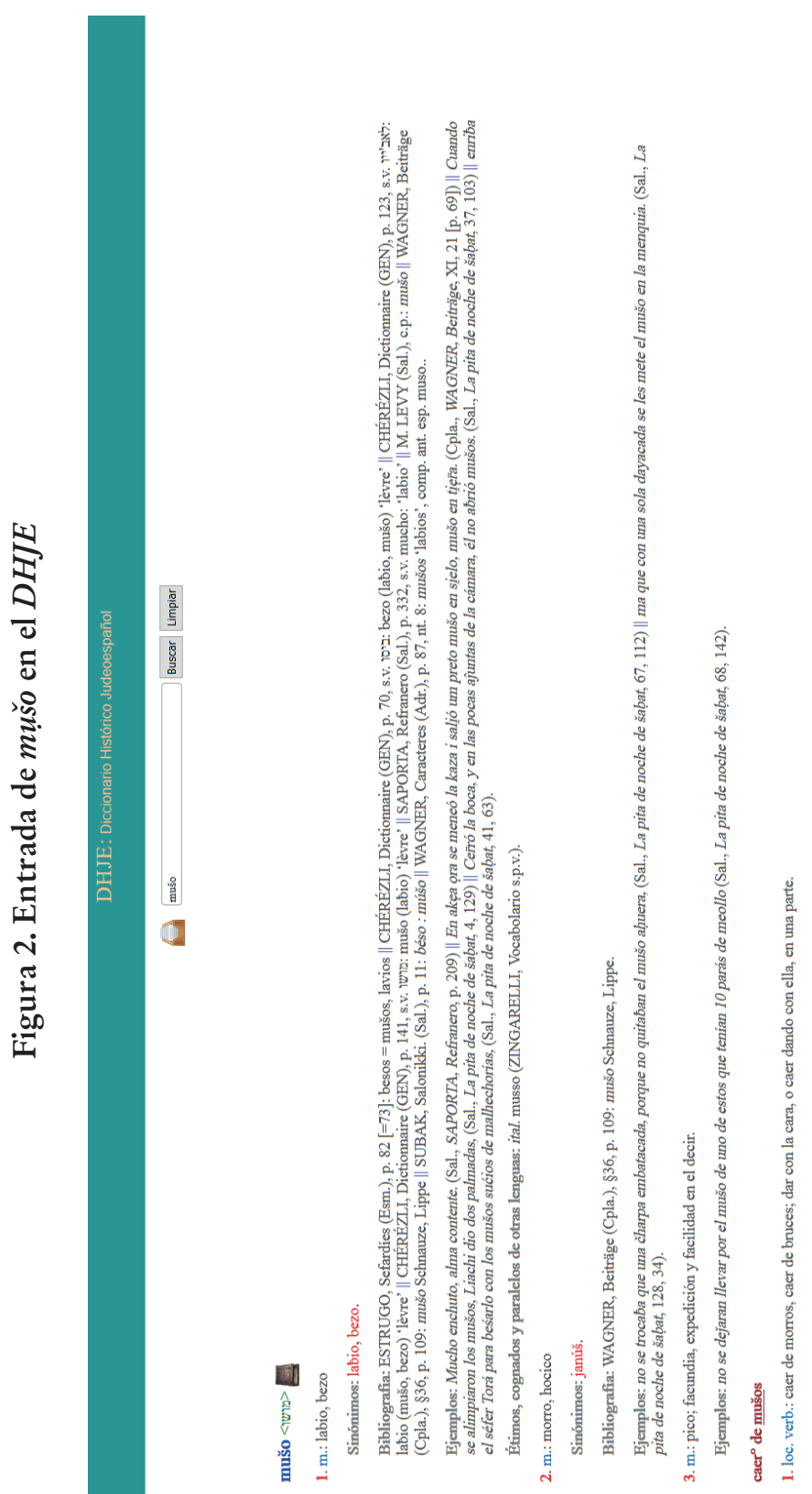


1) en primer lugar, la presencia en el texto de un dilatado número de unidades pluriverbales que o bien no se consideran UF o bien, dependiendo de la perspectiva teórica que se siga, pueden tener un carácter fraseológico dudoso, dado, por ejemplo, el débil grado de fosilización o la transparencia entre los elementos de los que se compone. Es necesario seguir indagando sobre el estatus de estas unidades, ya que, teniendo en cuenta el modo como el autor las presenta parecen ser unidades complejas:

\section{Tabla 4. Unidades de dudoso carácter fraseológico en El Trajumán}

\begin{tabular}{|l|}
\hline calor atagantada (p. 90) \\
\hline dụro de servịr (p. 93) \\
\hline aire repośado (p. 93) \\
\hline
\end{tabular}

2) en segundo lugar, la influencia de los equivalentes en alemán presentados por Papo en la selección y presentación de la información lingüística en judeoespañol. La obra de nuestro autor presenta el interés añadido que supone la comparación permanente con la lengua de contacto más importante para la comunidad sefardí de Viena: el alemán; contacto, que, por otra parte, no ha recibido hasta ahora la atención debida, y es todavía hoy terra incognita en la investigación sobre del judeoespañol. En este sentido, cabe decir que el hecho de que algunas unidades léxicas presentadas por el autor parezcan ser traducciones literales de unidades del alemán (como vor: antes de; über: por encima de; deshalb: por eso, entre otras) obliga a indagar en la relación que hubo entre ambas lenguas y en la influencia que aquella ejerció sobre esta en nuestro autor. ¿Puede extrapolarse esta influencia de forma más general al judeoespañol de Viena? Si, por ejemplo, miramos el equivalente en alemán que da Papo para cara a cara, vemos que esta unidad no puede considerarse equivalente a la locución en español cara a cara, tal como la definen en el DLE (s.v. cara): 'en presencia de alguien, descubiertamente' o en el DFDEA: 'Encuentro de dos perss. en que se hablan o se enfrentan abiertamente'. En este caso, parece ser más 
adecuado definirla a partir del significado de su equivalente alemán: 'a solas' (como en francés en tête à tête; o en portugués: cara a cara y face a face). Asimismo, si examinamos el equivalente alemán de a punto (gerade zur Zeit), concluimos que la unidad del judeoespañol tampoco equivale a la locución española a punto: 'Con la prevención y disposición necesarias para que algo pueda servir al fin a que se destina' o 'A tiempo, oportunamente' (DLE); 'En el estado o forma perfectos o correctos' y 'En el momento oportuno' (DFDEA, p. 710). Por esto, la definición propuesta en este caso es la siguiente: 'En el momento exacto'.

Tabla 5. Ejemplos de posibles calcos semánticos del alemán en UF de El Trajumán.

\begin{tabular}{lllll}
\hline Unidad & \multicolumn{1}{c}{ Contexto } & $\begin{array}{l}\text { Ubicación en el } \\
\text { texto }\end{array}$ & Clasificación & Definición \\
\hline $\begin{array}{l}\text { Cara a } \\
\text { cara }\end{array}$ & $\begin{array}{l}\text { cara a cara, unter } \\
\text { vị[e]r Aụgen (44) }\end{array}$ & $\begin{array}{l}\text { "V. Adverbios } \\
\text { y frases } \\
\text { adverbiales" }\end{array}$ & $\begin{array}{l}\text { Loc. } \\
\text { adverbial }\end{array}$ & 'A solas' \\
A punto & $\begin{array}{l}\text { a_pụnto, gerade zụr } \\
\text { "Vel Adverbios }\end{array}$ & $\begin{array}{l}\text { Loc. } \\
\text { y frases } \\
\text { adverbiales" }\end{array}$ & $\begin{array}{l}\text { 'En el } \\
\text { momento } \\
\text { exacto' }\end{array}$ \\
\hline
\end{tabular}

Por ello, es clave tener presentes los equivalentes en alemán que presenta Papo en el momento de reflexionar sobre la forma, la definición y los posibles equivalentes en español de las unidades del judeoespañol.

Para concluir, quisiéramos destacar que nuestra contribución pretende que las soluciones que damos a las cuestiones que acabamos de señalar permitan avanzar en el conocimiento de la fraseología judeoespañola, una tarea urgente y necesaria, dada la gran laguna existente en la bibliografía especializada. 


\section{Referencias bibliográficas}

Alonso Ramos, Margarita

2004 Las construcciones con verbo de apoyo. Madrid: Visor.

Álvarez López, Cristóbal José

2017 "Estudio lingüístico del judeoespañol en la revista «Aki Yerusbalayim»”. Tesis doctoral. Universidad de Sevilla, España.

August-Zarebska, Agnieszka

2011 "La imagen del judaísmo reflejada en el refranero judeoespañol”. Estudios Hispánicos. 19, 91-102.

BALLy, Charles

[1909] 1951 Traité de stylistique française. Ginebra: Georg et Cie.

Bunis, David

1992 "The Language of the Sephardim: A Historical Overview". En Moreshet Sepharad: The Sephardi Legacy. Ed., Haim Beinart. Jerusalem: The Magnes Press, 399-422.

BÜRKI, Yvette

2006 "El discurso periodístico de la prensa judeoespañola del siglo XIX”. Revista internacional de lingüistica iberoamericana. 8, 53-56.

BÜRKI, Yvette

2016 “El judeoespañol, ¿una variedad olvidada?”. Estudios de Lingüistica del Español. 37, 149-175.

Cantera Ortiz de Urbina, Jesús

1997 “El refranero sefardî”. Paremia. 6, 153-162.

Cantera Ortiz de Urbina, Jesús

2002 "Aportación cultural del refranero sefardí”. En Judaísmo hispano: Estudios en memoria de José Luis Lacave Riaño. Vol. I. Ed., Elena Romero. Madrid: CSIC, 341-351.

Cantera Ortiz de Urbina, Jesús

2004 Diccionario Akal del Refranero sefardí. Madrid: Akal.

Carracedo, Leonor y Elena Romero Castelló

1981 "Refranes publicados por Ja'acob A. Joná (edición concordada) y Bibliografía del Refranero sefardí”. Sefarad: Revista de Estudios Hebraicos y Sefardies. 41. 3, 389-560. 
Corominas, Joan y Juan Antonio Pascual

1980 Diccionario crítico etimológico castellano e bispánico. 6 Vols. Madrid: Gredos.

CORPAS PASTOR, Gloria

1996 Manual de fraseología española. Madrid: Gredos.

Echenique Elizondo, María Teresa et al. (eds.)

2016 Fraseología española: diacronía y codificación. Madrid: Anejos de la Revista de Filología Española.

Echenique Elizondo, María Teresa et al. (eds.)

2017 La fraseología a través de la bistoria de la lengua española y su bistoriografía. Valencia: Tirant Humanidades.

Echenique Elizondo, María Teresa et al. (eds.)

2018 Cómo se hacen las unidades fraseológicas: continuidad y renovación en la diacronía del espacio castellano. Berlín: Peter Lang.

García Moreno, Aitor (dir.)

$\mathrm{s} / \mathrm{f}$ Diccionario Histórico del Judeoespañol (DHJE). Consultado:

17 de septiembre de 2019. <http://www.esefardic.es/dhje>

García Moreno, Aitor y Francisco Javier Pueyo Mena

s/f Corpus Histórico Judeoespañol (CORHIJE). Consultado: 17 de septiembre de 2019. <http://www.esefardic.es/corhije>

García-Page Sánchez, Mario

2008 Introducción a la fraseología española. Estudio de las locuciones. Barcelona: Anthropos.

Gómez Capuz, Juan

2009 "El tratamiento del préstamo lingüístico y el calco en los libros de texto de bachillerato y en las obras divulgativas". Tonos. Revista electrónica de estudios filológicos. 17. Consultado: 20 de septiembre de 2019. <http://www.tonosdigital.com/ojs/ index.php/tonos/article/viewFile/294/203>

HASSÁN, Iacob M.

1978 “Transcripción normalizada de textos judeoespañoles”. Estudios Sefardies. 1, 147-150. 
Hernández Socas, Elia, Carsten Sinner y Encarnación Tabares Plasencia 2010

"El Trajumán de Michael Papo (1884)". En Los sefardíes ante los retos del mundo contemporáneo. Identidad y mentalidades. Eds., Paloma Díaz-Mas y María Sánchez Pérez. Madrid: CSIC, 333-344.

Heuer, Renate

1984 Bibliographia Judaica: L-R. Tomo II. Fráncfort del Meno: Campus-Verlag.

KAYSERLING, Meyer

[1890] 2001 Biblioteca española-portugueza-judaica. Pamplona: Analecta [reimpresión facsimilar de la edición de Strasbourg: C. J. Trübner].

Koch, Peter y Wulf Oesterreicher

2007 Lengua hablada en la Romania: español, francés, italiano. Madrid: Gredos.

KoIke, Kazumi

2001 Colocaciones léxicas en el español actual: estudio formal y léxico-semántico. Alcalá de Henares: Universidad de Alcalá.

KoIke, Kazumi

2011 "Tipología de las colocaciones verbonominales: de las colocaciones a las locuciones verbales". Takushoku Language Studies. 125, 1-39.

LeVY, Isaac

1969 Prolegomena to the Study of the Refranero Sefardi. Nueva York: Las Américas Pub.

LIPPE, Chaim David

1881 Bibliographisches Lexicon der gesammten jüdischen Literatur der Gegenwart und Adress-Anzeiger: ein lexicalisch geordnetes Schema mit adressen von Rabbinen, Predigern, Lebrern, Cantoren, Schriftstellern, Freunden und Förderern der jüdischen Literatur in der alten und neuen Welt.Viena: Löwy.

LÓPEZ SIMÓ, Mireia

2016 "Fórmulas de la conversación. Propuesta de definición y clasificación con vistas a su traducción español-francés, francés-español”. Tesis doctoral. Universidad de Alicante, España. 
Minervini, Laura

2006 "El desarrollo histórico del judeoespañol”. Revista Internacional de Lingüistica Iberoamericana. IV. 2(8), 13-34.

Moliner, María

1996 Diccionario de uso del español. Madrid: Gredos.

Montoro del Arco, Esteban Tomás

2006 Teoría fraseológica de las locuciones particulares. Las locuciones prepositivas, conjuntivas y marcadoras en español. Fráncfort del Meno: Peter Lang.

Montoro del Arco, Esteban Tomás

2017 "La intersección entre composición y fraseología: apuntes historiográficos". En La fraseología a través de la bistoria de la lengua española y su historiografía. Eds. M. ${ }^{a}$ Teresa Echenique Elizondo et al. Valencia: Tirant Humanidades, 213-245.

Nehama, Joseph

1977 Dictionnaire judéo- espagnol. Madrid: Instituto Arias Montano.

NeZirovic, Muhamed

1992 "El refranero judeoespañol inédito de Sarajevo de Benjamín / Moisé / Samokovlija / Muhamed Nezirovic”. En Actas del II Congreso Internacional de Historia de la lengua española. Tomo II. Eds., Manuel Ariza Viguera et al. Madrid: Pabellón de España, 241-249.

NúÑEZ BAYO, Zaida

2016 "Las fórmulas oracionales en el español coloquial”. Tesis doctoral. Universidad de Alcalá, España.

Oesterreicher, Wulf

2002 "El español, lengua pluricéntrica: perspectivas y límites de una autoafirmación lingüística nacional en Hispanoamérica. El caso mexicano". Lexis. XXVI. 2, 275-304.

PAPO, Michael Menahem

1884 El Trajumán. o livro de converśación en español y alemán (nemŝesco) por provecho de muchos señores del Oriente que viajan a-la Nemsia recoǵido de los mijores livros de converśación que [b]ay en ditas lenguas por el minor: Menabem b. Michael Papo. Viena: Jacob Schlossberg. 
PenAdÉs Martínez, Inmaculada

2006 "Las locuciones interjectivas en la fraseología española". En Caminos actuales de la historiografía lingüistica: actas del $V$ Congreso Internacional de la Sociedad Española de Historiografía lingüistica. Vol. 2. Coord., Antonio Roldán Pérez. Murcia: Universidad, 1197-1208.

Penadés Martínez, Inmaculada

2012 Gramática y semántica de las locuciones. Alcalá de Henares: Servicio de Publicaciones de la Universidad de Alcalá.

PENADÉs MarTínez, Inmaculada

2017 "El concepto de colocación a la luz de las colocaciones del tipo verbo más locución adverbial”. Revista de Filología Hispánica. Número extraordinario monográfico. 33.3, 963-991. <https:// doi.org/10.15581/008.33.3.963-91>

Quintana Aldina

1997 "Diatopische Variation des Judenspanischen in den Balkanländern und in der Türkei”. Nene Romania. 19. Judenspanish II, 47-65.

QuinTANA, Aldina

1999 "Proceso de recastellanización del Judesmo". En Jewish Studies at the Turn of the 20th Century: Proceedings of the Sixth EAJS Congress, Toledo, 1998. 2 Vols. Eds., Judit Targarona Borrás y Ángel Sáenz Bardillos. Leiden: Brill, 593-602.

Quintana, Aldina

2002 "Geografía lingüística del judeoespañol de acuerdo con el léxico”. Revista de Filología Española. LXXXII. 1-2, 105-138.

Quintana, Aldina

2006a Geografía lingüística del judeoespañol. Estudio sincrónico y diacrónico. Berna: Peter Lang.

Quintana, Aldina

2006b "Variación diatópica en judeoespañol”. Revista Internacional de Lingüística Iberoamericana. IV. 2. 8, 77-97.

Quintana, Aldina

2010 "El judeoespañol, una lengua pluricéntrica al margen del español”. En Los sefardíes ante los retos del mundo contem- 
poráneo. Identidad y mentalidades. Eds., Paloma Díaz-Mas y María Sánchez Pérez. Madrid: CSIC, 33-54.

QuintanA, Aldina

2011 "Nishkaha, dankave, marafet grande, pepino muevo, adoneba tu padre! y otras unidades léxicas del sexolecto masculino del judeoespañol coloquial de Bursa (Turquía)”. En Lexicología y lexicografía judeoespañolas. Eds., Winfried Busse y Michael Studemund-Halévy. Berna: Peter Lang, 215-236.

Real Academia Española

$\mathrm{s} / \mathrm{f} \quad$ Corpus diacrónico del español (CORDE). Consultado: $18 \mathrm{de}$ septiembre de 2019 http://corpus.rae.es/cordenet.html

Real Academia Española y Asociación de Academias de la Lengua ESPAÑOLA

s/f Diccionario de la lengua española (DLE). Consultado: 18 de septiembre de 2019. <https://dle.rae.es>

Romano, Samuel

1933

Dictionary of spoken Judeo-Spanish / French / German /. With an introduction on phonetics and word formation. Tesis doctoral. University of Zagreb, Croacia. [fotocopia del manuscrito original. Misgav Yerushalayim: Institute for Research on the Sephardi and Oriental Jewish Heritage, 1995].

Romero Castelló, Elena (ed.)

2001 Andanzas y prodigios de Ben-Sirá. Edición del texto judeoespañol y traducción del texto hebreo. Madrid: CSIC.

RuIZ GuRILlo, Leonor

1998 La fraseología del español coloquial. Barcelona: Ariel.

SANROMÁn Vilas, Begoña

2014 "La alternancia DAR/HACER en construcciones con verbo de apoyo y nombre de comunicación”. Borealis: An International Journal of Hispanic Linguistics. 3. 2, 185-222. <https://doi. org/10.7557/1.3.2.2946>

SAPORTA y Beja, Enrique

1978 Refranes de los judios sefardies y otras locuciones típicas de los judios sefardíes de Salónica y otros sitios de Oriente. Barcelona: Ametller. 
SBARBI, José María

1922 Diccionario de refranes, adagios, proverbios, modismos, locuciones, y frases proverbiales de la lengua española. Madrid: Librería de los sucesores de Hernando.

SCANDOLA, Viviana

2003 "Hacia una «historia de la fraseología española»". Res Diachronicae. 2, 359-370.

Schmid, Beatrice

2008 "La lengua sefardí en su plenitud”. En Sefardies: Literatura y lengua de una nación dispersa. Ed., Elena Romero. Cuenca: Ediciones de la Universidad de Castilla-La Mancha, 51-79.

Seco, Manuel, Olimpia Andrés y Gabino Ramos

2017 Diccionario fraseológico documentado del español actual (DFDEA). Madrid: Jdej Editores.

Sevilla Muñoz, Julia y Manuel Sevilla Muñoz

2000 "Fuentes paremiológicas francesas y españolas de la segunda mitad del siglo XIX”. Estudos de Literatura Oral. 6, 189-206.

Sinner, Carsten; Elia Hernández Socas; y Encarnación Tabares Plasencia 2014a “Trazos ideológicos en El Trajumán de Michael Papo". Boletín Hispánico Helvético. 23, 247-272.

Sinner, Carsten; Elia Hernández Socas; y Encarnación Tabares Plasencia 2014b "La función de las glosas en el Trajumán de Papo". Zeitschrift für Romanische Philologie. 130. 2, 397-429.

Sinner, Carsten y Encarnación Tabares Plasencia

2016 "El problema de las variantes fraseológicas desde la perspectiva de la lingüística de variedades”. RLA. Revista de Lingüística Teórica y Aplicada. 54. 2, 13-41. <https://doi.org/10.4067/ S0718-48832016000200002>

Studemund-Halévy, Michael y Gä̈lle Collin

2008 "Sefarad sur les rives du Danube. Vienne et la littérature judéo-espagnole”. Miscelánea de Estudios Árabes y Hebraicos. Sección Hebreo. 57, 149-211.

Tabares Plasencia, Encarnación

2018 "La fraseología jurídica en el Libro de buen amor". Estudis Romànics. 40, 59-88. 
Tabares Plasencia, Encarnación

2020 "Fraseología jurídica en un corpus diacrónico de textos literarios españoles y su representación fraseográfica”. Representación de la fraseología en herramientas digitales: problemas, avances, propuestas, M. De Beni (ed.). Círculo de Lingüística Aplicada a la Comunicación. 82, 69-92. <https:// doi.org/10.5209/clac.68964>

Tabares Plasencia, Encarnación; Carsten Sinner; y Elia Hernández Socas 2012 "La expresión del tiempo en El Trujamán de Michael Papo (Viena, 1884)". En Tiempo y espacio y relaciones espacio-temporales en judeoespañol. Eds., Yvette Bürki y Carsten Sinner. München. Peniope, 63-76.

Varela, Fernando y Hugo Kubarth

1994 Diccionario fraseológico del español moderno. Madrid: Gredos.

VINOGRÁDOV, Víktor Vladimírovich

1947 "Ob osnovnykh tipakhfrazeologicheskikh yedinits v russkom yazyke”. En Russkiy yazyk (Grammaticheskoye ucheniye o slove). Moscú: Uchpedguiz, 21-28.

Wininger, Salomon

1929 Große Jüdische National-Biographie mit nabezu 13.000 Lebensbeschreibungen nambafter jüdischer Männer und Franen aller Zeiten und Länder. Ein Nachschlagewerk für das jüdische Volk und dessen Freunde. Tomo IV. Chernivtsi: Tip. Arta.

Zamora Muñoz, Pablo

1998 "Las frases idiomáticas pragmáticas italianas: los marcos de situación y sus equivalencias en español”. Estudios Románicos. 10, 107-126.

Zuluaga, Alberto

1980 Introducción al estudio de las expresiones fijas. Fráncfort del Meno: Peter Lang.

Recepción: 09/05/2020

Aceptación: 03/08/2020 